\title{
JACQUES COPEAU: UMA VIDA DEDICADA À RENOVAÇÃO DO TEATRO
}

Evandro Luis Teixeira ${ }^{1}$

Resumo: O presente artigo é resultado do Projeto de Pesquisa Poética, Ética e Estética na Pedagogia Teatral de Jacques Copeau - financiado pelo PROBIC/UDESC - que se propõe a pesquisar os textos de Jacques Copeau ainda não disponíveis em Língua Portuguesa, através das traduções do orientador Prof. Dr. José Ronaldo Faleiro ${ }^{2}$ e de outros autores que discutem a sua obra. O objetivo deste artigo é possibilitar maiores esclarecimentos sobre a vida e a obra de Jacques Copeau.

Palavras Chave: Jacques Copeau - Teatro Françês

Filho de uma família burguesa de fabricantes e comerciantes, Jacques Copeau nasceu no dia 4 de fevereiro de 1879, no número 76 da rua do Faubourg Saint-Dennis em Paris, na França. Copeau, ao que tudo indica, teve uma infância povoada de sonhos, dominada por uma viva sensibilidade, um senso agudo de observação e uma imaginação fértil.

Jacques Copeau realizou seus primeiros estudos no Lycée Condorcet (de 1887 a 1896). Escreveu sua primeira peça nessa época: Brouillard du matin [Cerração matinal], representada em 27 de março de 1897 no Novo Teatro, pelos seus colegas, durante uma festa da associação dos alunos do Liceu Condorcet. Nesse período Copeau conheceu a jovem dinamarquesa Agnès Thomsen e se apaixonou por ela.

Em 1897, após passar nos exames, Copeau ingressou no curso de Filosofia da Sorbonne. Mas não chegou a concluí-lo, abandonando-o no ano seguinte.

A morte de seu pai (1901) parecia desviá-lo de seus objetivos, incitando-o a dirigir os negócios da família. Copeau, desconsiderando os avisos de sua mãe, casou-se com Agnès na Dinamarca; onde nasceu sua primeira filha, Marie-Hélène. Durante essa época, Copeau, após se impressionar com os livros de André Gide, começou a se corresponder com o escritor.

Em 1903, a jovem família de Copeau voltou para a França. Copeau passou uma temporada no interior, onde continuou a escrever ao mesmo tempo em que dirigia os negócios da família. Ele se aproximou de Gide enquanto freqüentava o meio intelectual parisiense fazendo seu nome como crítico.

1 Acadêmico do curso de Artes Cênicas da Udesc, bolsista de iniciação científica do PROBIC/ CNPq

${ }^{2}$ José Ronaldo FALEIRO é doutor em Artes do Espetáculo pela Universidade de Paris X - Nanterre. Foi coordenador geral do Primeiro e Segundo Festivais Universitários de Teatro de Blumenau. É diretor e professor de Teatro. Leciona no Centro de Artes (CEART) da Universidade do Estado de Santa Catarina (UDESC). 
De volta a Paris, em 1905, Copeau trabalhou na galeria de Georges-Petit, enquanto colaborava como crítico de arte e crítico dramático. Foi através da análise do teatro contemporâneo e do seu aguçado senso crítico que teve artigos publicados em diversas revistas. Em 1905 nasceu sua segunda filha, Hedvig.

O ano de 1907 representou um considerável progresso na carreira de crítico para Copeau, Jacques Rouché lhe confiou em 1907 a crônica dramática de La Grande Revue [A Grande Revista] na qual sucedeu a Léon Blum. É também o ano do nascimento de seu filho Pascal. Com a venda da fábrica da família em Racourt, Copeau conseguiu exercer suas atividades literárias com maior afinco.

Em 1908, ao lado de escritores de destaque da época, fundou La Nouvelle Revue Française (N.R.F.) [A Nova Revista Francesa]. Através dessa revista Copeau difundiu grande parte de suas reflexões.

Em 1910, Copeau comprou uma propriedade em Limon, em Seine-et-Marne, longe das distrações de Paris. Nessa época, trabalhou ao lado de Jean Croué sobre uma adaptação do romance Os Irmãos Karamazov de Fiodor Dostiesvski, que ele acabou no fim de 1910. No dia 6 de abril de 1911, no Teatro das Artes, sob a direção de Jacques Rouché, foi representado o drama em cinco atos, adaptado por Copeau.

Em setembro de 1913 Copeau publicou «Un Essai de Rénovation Dramatique» [Uma tentativa de renovação dramática] na N.R.F., um manifesto que anunciava a sua determinação de «[...] construir em bases absolutamente intactas um teatro novo [...] $»^{3}$, em que os grandes clássicos seriam apresentados «[...] como antídoto para a falta de gosto [...] $»^{4}$. Nesse manifesto, Copeau prestou homenagem a Antoine, a Rouché, e aos inovadores estrangeiros como Fuchs, Reinhardt, Meyerhold e Stanislavski. No entanto, afastou-se deles, pregando o retorno a uma convenção feita de simplicidade e naturalidade, repudiando as fórmulas decorativas e negando a importância de toda e qualquer maquinaria: «Que os outros prestígios desapareçam e, para a obra nova, que nos deixem um tablado nu! ».

Impelido pelo sentimento de indignação perante a situação em que se encontrava o teatro francês de sua época, Copeau dedicou esforços para a fundação de um novo teatro: o Théâtre du Vieux-Colombier [Teatro do Velho Pombal]. Em julho de 1913, para preparar a abertura do teatro,

\footnotetext{
${ }^{3}$ Id. ibid. p. 21.

${ }^{4}$ Id. ibid. p. 25.
} 
Copeau viajou com uma jovem equipe de atores a Limon, em Seine-et-Marne, para desenvolver e ensaiar duas peças: La Femme tuée par la douceur [A Mulher Assassinada com Suavidade], do escritor Thomas Heywood, e L'Amour médecin [O Amor Médico], de Molière, que viriam a compor o repertório de seu teatro. Copeau reuniu uma companhia jovem. Entre aqueles que o acompanharam, estavam Louis Jouvet, Charles Dullin e Suzanne Bing. Essa empresa representou o marco inicial das concepções de educação e formação do ator - através de leituras em voz alta, estudos dos textos, ginástica e jogos - realizadas por Jacques Copeau ao longo de sua vida.

Durante a primeira temporada (1913-1914), Copeau encenou treze espetáculos nos quais estrelou como ator representando nove papéis, organizou conferências, leituras e matinês musicais e poéticas. No final da temporada, no dia 18 de maio de 1914, o Teatro do Vieux-Colombier representou A Noite de Reis, de Shakespeare.

Em 1914 o Vieux Colombier suspendeu suas atividades por causa da Primeira Guerra Mundial. Copeau, Louis Jouvet e Charles Dullin foram chamados para servir às forças armadas francesas. Em setembro de 1915, após ser dispensado pelo exército, Copeau foi ao encontro de grandes mestres do teatro que exerceram influências no modo de trabalho do Vieux-Colombier: Gordon Craig em Florença e Adolphe Appia na Suíça.

Depois disso, Copeau e Suzanne Bing deram início às suas primeiras tentativas de formar uma Escola de Arte Dramática. No outono de 1915, no Clube de Ginástica Rítmica em Paris, sob a direção de Paulet Thévenaz, Copeau fez sua primeira experiência prática com um grupo de 12 crianças e a partir dessa experiência criou um plano para aplicar em sua escola. Nesse momento, a Rítmica de Emile Jaques-Dalcroze desempenhava um papel importante na prática de Copeau. Ele também se interessava pelo jogo infantil e pelas relações entre jogo e teatro.

Ainda em meio à guerra, Copeau se correspondia com seu colaborador Louis Jouvet, que lutava no front. Eles desenvolveram, auxiliados por Theo Van Rysselberghe, dispositivos cênicos chamados de tréteau [tablado] e loggia [camarote], compostos em madeira, e que serviriam para obter o aproveitamento total do espaço.

Por solicitação do governo francês, Copeau aceitou, em 1917, uma missão cultural nos Estados Unidos, com o objetivo de neutralizar a propaganda alemã e valorizar a cultura francesa. Copeau passou uma temporada de quatro meses nos EUA, onde proferiu apresentações, conferências e leituras. Obteve o apoio para a direção do Teatro Francês de Nova Iorque e voltou para a Europa a fim de reagrupar e reorganizar a Companhia do Vieux Colombier. Copeau compôs e ensaiou um novo repertório com sua trupe parcialmente reconstituída, já com Dullin e Jouvet desmobilizados. Ele e Jouvet trabalharam nos princípios de um novo dispositivo cênico.

No dia 27 de novembro de 1917, foi inaugurado, no Garrick Theatre, o Vieux Colombier de Nova 
Iorque, onde Copeau e Jouvet materializaram a idéia de estrutura cênica. Esse novo ambiente não impediu que eles criassem uma cenografia simples e funcional, e a partir da qual obtivessem diferentes espaços num único lugar. No decorrer de duas temporadas (1917-1919) a companhia representou quarenta e quatro peças (muitas vezes forçada por um repertório encomendado) e fez trezentas e quarenta e cinco apresentações. Copeau terminou sua estada nos EUA com uma turnê de conferências no Oeste americano. No dia 7 de abril de 1919 inaugurou a Associação dos Amigos do Vieux Colombier de Nova Iorque. E, em junho, regressou à França.

Ao retornar à Paris no final de 1919, Copeau promoveu a reabertura do Vieux Colombier. Criou os Ateliês de eletricidade e carpintaria, sob a direção de Jouvet, para servir tanto ao teatro quanto ao público.

Copeau trabalhou com Louis Jouvet para a transformação do palco do Vieux-Colombier, na tentativa de instalar ali um dispositivo arquitetural fixo já experimentado em Nova Iorque. Esse dispositivo deveria proporcionar um maior aproveitamento do espaço de cena e atender exigências dramatúrgicas. Realizadas as mudanças, nada restou da forma original da moldura da caixa cênica do antigo Vieux-Colombier. Copeau e Jouvet eliminaram a boca de cena e construíram uma escada frente ao palco, com o objetivo de obter uma relação mais direta entre a cena e o público. Depois das reformas, Copeau foi criticado pela terrível acústica do teatro (consequiência de cobrir o chão de cimento). Ao que tudo indica, Copeau mostrou ressentimentos por não ter tido autoridade suficiente para impedir graves erros.

Copeau e Suzanne Bing fizeram novas tentativas de montar uma Escola de Arte Dramática. Em 1920 Copeau escreveu várias notas sobre as suas experimentações pedagógicas. Esse período representou uma etapa fundamental na sua reflexão sobre a pedagogia teatral. «A idéia da Escola e a idéia de teatro são uma só idéia. Nasceram juntas », afirmou Copeau em 1920. A sua tentativa pedagógica já havia começado, efetivamente, em 1913, durante o verão que precedeu a abertura do Vieux-Colombier, quando ele instalou a sua jovem companhia na sua propriedade do Limon. Copeau havia estabelecido um esquema de ensino no qual se alternavam estudos de texto e exercícios físicos. A Escola do Vieux Colombier só surgiu oficialmente a partir de 1920, ainda chamada de « escola embrionária ».

Copeau aumentou a Escola com a colaboração de Jules Romains, todas as regras do ensino dramático foram estabelecidas, assegurando as finalidades e funcionamento das atividades. A Escola foi dividida em três segmentos, que eram destinados a cursos específicos: a divisão A comportava alunos iniciantes a partir de 12 anos; a divisão B comportava alunos iniciados acima de 18 anos; e a divisão $\mathrm{C}$ era para aqueles alunos que não se dedicavam à atuação, mas que poderiam recolher benefícios de suas atividades - um espaço reservado para autores, escritores e críticos.

A Escola, sob a direção de Suzanne Bing, estava trabalhando em atividade intensa. Até DAPesquisa, Florianópolis, v.2, n.4, p. 062-068, 2007. 
1924, Copeau produziu espetáculos, conferências, exposições, palestras e cursos. Foi um período muito rico em experiências, que o consagrou como pensador e pedagogo teatral. Inquieto, estava sempre em busca de uma estrutura que lhe desse condições espaciais e temporais de dedicar-se à renovação do teatro através da formação do ator. Mas Copeau estava insatisfeito e anunciou o fechamento anual do Vieux-Colombier. Sua intenção era dedicar-se por completo à Escola e ao trabalho de pesquisa. Em maio, no dia 15, apresentou o espetáculo de encerramento em benefício da École du Vieux-Colombier. Este foi o último dia de Jacques Copeau no Vieux-Colombier.

No dia 13 de setembro de 1924, Copeau visitou e alugou o castelo de Morteuil, por Demigny (Saône-et-Loire), com o intuito de transplantar para lá a Escola. Transmitiu a companhia do Vieux Colombier à Louis Jouvet em 23 de setembro e partiu para a Borgonha em outubro do mesmo ano. Acompanhado de trinta e três pessoas (entre elas, Michel Saint-Denis, Léon Chancerel e Georges Chennevière, Marie-Hélène Copeau, Jean Dasté, Aman Maistre e Étienne Decroux), com o objetivo de pesquisar a linguagem teatral. O retiro na Borgonha é primeiramente uma espécie de laboratório, que deveria funcionar como um prolongamento da Escola. A formação e a educação continuaram a ocupar o primeiro plano. Mas, por razões financeiras, Copeau foi obrigado a renunciar a seu projeto em fevereiro de 1925. Alguns daqueles que o seguiram até a Borgonha resolveram permanecer com ele em Pernand-Vergelesses (de 1925 a 1929) e passaram a ser chamados pelos habitantes locais de Copiaus. Dentre eles, um pequeno núcleo retornou mais tarde a Paris e constituiu, em 1931, o Théâtre des Quinze [Teatro dos Quinze] ou o grupo Quinze du Vieux Colombier [Quinze do Velho Pombal], já sem a direção de Copeau.

Os Copiaus apresentaram pequenos espetáculos em Lille, e depois, com um novo repertório, em Demigny e noutras pequenas cidades da região, além da celebração da festa dos vinhos em Nuits-Saint-Georges. Os Copiaus afirmaram com êxito as experiências de descentralização, promovendo excursões pelas cidades e povoados, apresentando o repertório que, de acordo com as propostas de um teatro popular defendidas por Copeau, variavam entre as pequenas farsas e os grandes clássicos. Copeau adaptou e escreveu para eles diversos espetáculos, entre os quais estavam L'Illusion [A Ilusão], encenado pelos Copiaus em 3 de outubro de 1926, e L'Anconitaine [Anconitana], de Ruzante.

Copeau realizou durante esse período turnês de conferências e de leituras no interior e no exterior da França. De passagem pelos Estados Unidos, encenou, no Theatre Guild de Nova Iorque, sua adaptação de Os Irmãos Karamazov.

Entre 1926 e 1929, Copeau realizou pesquisa com Os Copiaus e turnês pela França, Suíça, Bélgica, Holanda, Inglaterra e Itália. Em junho de 1929, Copeau dissolveu os Copiaus.

Aos cinqüenta anos, Copeau desejava pôr em prática a sua experiência numa esfera mais oficial. Foi iniciada então uma primeira campanha para levar Jacques Copeau à direção da DAPesquisa, Florianópolis, v.2, n.4, p. 062-068, 2007. 
Comédie-Française. Ela fracassou. Copeau encenou CEdipus rex [Édipo Rei], de Igor Stravinski, na Ópera de Paris, em 1929. Depois disso, continuou a exercer a atividade de crítico dramático. Voltou a Pernand, com o intuito de escrever artigos para revistas e jornais. Em 1930, retomou as turnês de conferências e de leituras.

Depois de um acidente ocorrido com Édouard Bourdet, administrador da ComédieFrançaise, em 14 de maio de 1940, Copeau foi nomeado “Administrador Provisório", após diversas campanhas pedindo pelo seu nome. Pouco tempo depois teve início a grande ofensiva alemã. A guerra e a Ocupação Nazista não permitiram que Copeau prosseguisse com o trabalho. Depois de ter montado Le Carosse du Saint-Sacrement [A Carruagem do Santo Sacramento], Le Cid [O Cid] (no qual contratou Jean-Louis Barrault para o papel de Rodrigo) e La Nuit des Rois [A Noite de Reis], foi forçado a pedir demissão em março de 1941, tendo permanecido no cargo por apenas dez meses. Após a demissão, voltou para a Borgonha ainda no mesmo mês.

Em 1941 Copeau publicou Le Théâtre Populaire [O Teatro Popular], um opúsculo que trata das formas teatrais populares ao longo da história do Teatro Ocidental e define as perspectivas de Copeau acerca da descentralização teatral. A partir desse ano até 1948, ele publicou ensaios, escreveu peças, encenou e interpretou novos espetáculos, sempre dando continuidade às suas turnês de conferências e leituras. Em julho de 1943, adaptou, encenou e interpretou Le Miracle du Pain doré [O Milagre do Pão Dourado], no Hospital de Beaune, para os quinhentos anos de sua fundação, utilizando um dispositivo cênico de André Barsacq. Terminou de escrever a sua peça sobre Francisco de Assis, Le Petit Pauvre [O Pobrezinho].

Após intensa atividade dedicada ao ofício do teatro, Jacques Copeau morreu no Hospital de Beaune no dia 20 de outubro de 1949. Foi enterrado quatro dias depois, em Pernand-Vergelesses.

\section{Bibliografia}

COPEAU, Jacques. Souvenirs du Vieux-Colombier [Lembranças do Vieux-Colombier]. Paris: Les Editions Latines, 1931. Tradução de José Ronaldo Faleiro. (inédito).

COPEAU, J. Registres I; Appels [Registros I; Apelos]. Textes recueillis et établis par Marie-Hélène Dasté et Suzanne Maistre Saint-Denis. Notes de Claude Sicard. [Textos coletados e estabelecidos por Marie-Hélène Dasté e Suzanne Maistre Saint-Denis. Notas de Claude Sicard]. Paris: Gallimard, 1974. - Trad. de José Ronaldo Faleiro (inédito).

. Registres III; Les Registres du Vieux Colombier. I (Première partie) [Registros III;

Os registros do Vieux Colombier \{Velho Pombal\}. I (Primeira parte)]. Textes recueillis et établis 
par Marie-Hélène Dasté et Suzanne Maistre Saint-Denis. Notes de Norman Paul. [Textos coletados e estabelecidos por Marie-Hélène Dasté e Suzanne Maistre Saint-Denis. Notas de Norman Paul]. Paris: Gallimard, 1979. - Trad. de José Ronaldo Faleiro (inédito).

Registres VI. L'École du Vieux-Colombier [Registros VI. A Escola do VieuxColombier]. Textes établis, présentés et notés par Claude Sicard. [Textos estabelecidos, apresentados e anotados por Claude Sicard.] Paris: Gallimard, 2000. Trad. de José Ronaldo Faleiro (inédito).

JOMARON, Jacqueline. Jacques Copeau: le tréteau nu [Jacques Copeau: o tablado nu], p. 731741, in JOMARON, Jacqueline (org.) Le Théâtre en France du Moyen Âge à nos jours [O Teatro na França da Idade Média aos nossos dias]. Prefácio de Ariane Mnouchkine. Paris: Armand Colin, 1992. - Tradução de José Ronaldo Faleiro (inédito). 